\title{
Indication that the behavioural responses of humpback whales to killer whale sounds are influenced by trophic relationships
}

\author{
Benjamin Benti ${ }^{1,2,3, *}$, Patrick J. O. Miller ${ }^{1}$, Martin Biuw ${ }^{4}$, Charlotte Curé ${ }^{3}$ \\ ${ }^{1}$ Sea Mammal Research Unit, Scottish Ocean Institute, University of St Andrews, St Andrews, Fife KY16 8LB, UK \\ ${ }^{2}$ Cognitive and Social Ethology Team, UMR 7247-85, CNRS, INRA, IFCE, University of Tours, 67037 Strasbourg, France \\ ${ }^{3}$ Acoustics Group, UMRAE, CEREMA-Université Gustave Eiffel, Laboratory of Strasbourg, 67035 Strasbourg, France \\ ${ }^{4}$ Institute of Marine Research, Fram Centre, PO Box 6606 Langnes, 9296 Tromsø, Norway
}

\begin{abstract}
Eavesdropping, the detection of communication signals by unintended receivers, can be beneficial in predator-prey interactions, competition, and cooperation. The cosmopolitan killer whale Orcinus orca has diverged into several ecotypes which exhibit specialised diets and different vocal behaviours. These ecotypes have diverse ecological relationships with other marine mammal species, and sound could be a reliable sensory modality for eavesdroppers to discriminate between ecotypes and thereby respond adaptively. Here, we tested whether humpback whales Megaptera novaeangliae in the Northeast Atlantic responded differently to playback of the sounds of 2 killer whale ecotypes, Northeast Atlantic herring-feeding killer whales representing food competitors and Northeast Pacific mammal-eating killer whales simulating potential predators. We used animal-borne tags and surface visual observations to monitor the behaviour of humpback whales throughout the playback experiments. Humpback whales clearly approached the source of herring-feeding killer whale sounds (5 of 6 cases), suggesting a 'dinner-bell' attraction effect. Responses to mammal-eating killer whale sounds varied with the context of presentation: playback elicited strong avoidance responses by humpback whales in offshore waters during summer ( 7 of 8 cases), whereas the whales either approached ( 2 of 4 cases) or avoided ( 2 of 4 cases) the sound source in inshore waters during winter. These results indicate that humpback whales may be able to functionally discriminate between the sounds of different killer whale ecotypes. Acoustic discrimination of heterospecific sounds may be widespread among marine mammals, suggesting that marine mammals could rely on eavesdropping as a primary source of information to make decisions during heterospecific encounters.
\end{abstract}

KEY WORDS: Acoustic eavesdropping - Playback - Trophic relationship - Killer whale · Orcinus orca $\cdot$ Humpback whale $\cdot$ Megaptera novaeangliae

\section{INTRODUCTION}

The ability to eavesdrop on acoustic signals, that is, the detection of communication signals by unintended receivers of the same or another species, can affect animal fitness (McGregor 1993). Gathering information through acoustic eavesdropping is likely to

\footnotetext{
*Corresponding author: benjamin.benti@protonmail.com
}

be particularly beneficial in predator-prey interactions, competition, and cooperation. Eavesdropping on species sharing similar prey may provide an indirect way to locate food patches (e.g. Übernickel et al. 2013, Pollock et al. 2017) or to avoid areas of highintensity competition (e.g. Evans et al. 2009). Potential prey may thwart predation attempts if they are

(C) The authors 2021. Open Access under Creative Commons by Attribution Licence. Use, distribution and reproduction are unrestricted. Authors and original publication must be credited. 
able to detect and identify acoustic cues informing them about predator presence and to adopt appropriate behaviours to reduce the risk of predation such as avoidance (e.g. Cummings \& Thompson 1971, Emmering \& Schmidt 2011), stealth (e.g. Rankin et al. 2013), or mobbing (e.g. Curé et al. 2012). Another way to reduce predation risk can be the detection and use of alarm calls released by other species within the prey community (e.g. Fuong et al. 2014, Magrath et al. 2015). Predators may in turn improve their foraging efficiency by reducing the production of acoustic cues that can be used by prey to detect and avoid them (e.g. Barrett-Lennard et al. 1996, Deecke et al. 2005).

The behavioural response upon receiving a signal also depends on context and may depend on the receiver's body condition, such as satiation level (e.g. Kern et al. 2017), its prior experience (e.g. Beattie \& Moore 2018), the behavioural activity it is engaged in (e.g. Goldbogen et al. 2013, Friedlaender et al. 2016), or ecological factors such as prey availability (e.g. Ellison et al. 2012, Friedlaender et al. 2016). Behavioural responses can also be influenced by senderrelated cues, such as the sender's species (e.g. Palmer \& Gross 2018), size (e.g. Pfefferle \& Fischer 2006), group size and composition (e.g. Payne et al. 2003), reliability (e.g. Kern et al. 2017), or current behaviour (e.g. Filatova et al. 2013). Moreover, the receiver's environment may also be important in shaping its responses, such as habitat topography (e.g. Perla \& Slobodchikoff 2002, Kern et al. 2017) or the size and composition of the receiver's social group (e.g. LaGory 1987).

Sound represents a primary information medium in the marine environment; light quickly fades with depth, whereas acoustic signals travel over large distances and experience little attenuation in seawater, especially in the lower part of the frequency spectrum. Many marine mammals rely on sounds for foraging (e.g. Barrett-Lennard et al. 1996, Miller et al. 2004), breeding (e.g. Smith et al. 2008, Herman 2017), and social coordination (e.g. Nousek et al. 2006, Jensen et al. 2011, Gero et al. 2016, King et al. 2018). Their hearing sensitivity over a wide frequency range allows them to detect acoustic signals produced by many other species (see Southall et al. 2019), such as potential prey, predators, or competitor species. This makes marine mammals particularly suitable model species for the study of interspecific acoustic eavesdropping. However, there have been far fewer studies on acoustic communication and eavesdropping in marine than in terrestrial systems, likely because of the intrinsic challenges in monitor- ing the behaviour of aquatic animals that spend most of their time underwater. The development of animal-borne multi-sensor tags, which enable the tracking of marine mammals and the recording of their underwater behaviour (e.g. Johnson \& Tyack 2003, Johnson et al. 2009), has made it possible to conduct such acoustic studies on wild marine mammals, for instance using playback experiments. Playback experiments, i.e. broadcasting sound stimuli and monitoring the behavioural responses of exposed animals, is a classic method to probe into the potential functions of animal vocalisations or to investigate sound discrimination in particular contexts (reviewed by Deecke 2006).

Playbacks of killer whale sounds to wild marine mammals have demonstrated anti-predator responses, such as avoidance (e.g. Fish \& Vania 1971, Deecke et al. 2002, Curé et al. 2013, 2015, Bowers et al. 2018) and apparent mobbing (e.g. Curé et al. 2012, Bowers et al. 2018, Curé et al. 2019), in numerous species. Killer whales are cosmopolitan apex predators known to prey on a wide range of marine organisms, including members of most families of marine mammals (Jefferson et al. 1991). However, the diet, social organisation, and behaviour of killer whales are variable, and not all interactions between killer whales and other marine mammal species are predatory (reviewed by Jefferson et al. 1991). Some killer whale populations, such as in the Northeast Pacific, present clearly delineated ecotypes, while the ecological status of other populations, in the Northeast Atlantic or the Southern Hemisphere for instance, remains unclear (reviewed by de Bruyn et al. 2013). Killer whale ecotypes around the world may exhibit specialised diets (e.g. Samarra et al. 2017) and present differences in their vocal behaviour (e.g. Deecke et al. 2005). Therefore, the sounds of killer whales can potentially provide a wide range of ecological information to other marine mammals. Marine mammal eavesdroppers may rely on acoustic cues to discriminate between killer whales of different ecotypes and respond functionally in accordance with their ecological relationship to the ecotype of the detected killer whale.

Indeed, different behavioural responses to playback of the sounds of different killer whale ecotypes have been described in 1 species of pinniped and in 1 species of toothed whale. Harbour seals Phoca vitulina in the Northeast Pacific avoided the source of the sounds of transient killer whales - local marine mammal predators - and unfamiliar fish-eating killer whales but did not react to the source of the sounds of familiar resident killer whales - local fish specialists 
that do not prey on seals (Deecke et al. 2002). Longfinned pilot whales Globicephala melas showed more severe anti-predator responses to unfamiliar calls from marine mammal-eating killer whales (MEKWs) than to sounds from familiar fish-eating killer whales (Curé et al. 2019). Harbour seals and long-finned pilot whales seem to have selectively habituated to the sounds of familiar killer whales which pose little predation risk because of their fish-dominated diets, while maintaining anti-predator responses to familiar predatory killer whales or unfamiliar killer whales (Deecke et al. 2002, Curé et al. 2019). Migratory cetaceans, including most baleen whale species, cover much larger areas than non-migratory marine mammal species and may therefore encounter more killer whale ecotypes in a greater diversity of contexts. For instance, humpback whales Megaptera novaeangliae in the Northern Hemisphere spend winter on tropical or subtropical breeding grounds and summer on high-latitude feeding grounds and generally migrate annually between these areas (Clapham \& Mead 1999). Killer whale sounds may signal to humpback whales the presence of predators, competitors, or killer whales without trophic relationships with them. Their behavioural responses may vary in type and in intensity depending on the ecotype of the killer whale and the context of the encounter (e.g. location, season, behavioural activity).

Here, we describe the behavioural responses of humpback whales to playback of killer whale sounds conducted in Norway, with particular focus on whether and how these responses varied according to killer whale ecotype. In the Northeast Atlantic, humpback whales feed from early summer to fall around Svalbard and Bear Island, and during winter in coastal Norway, before migrating to lower-latitude areas to breed (Clapham \& Mead 1999). We conducted playback experiments off Spitsbergen in early summer and in the Norwegian fjords during winter. We broadcast the feeding sounds of 2 killer whale ecotypes: herring-feeding killer whales (HFKWs) from Norway, representing a familiar population posing a low risk of predation, and MEKWs from the Northeast Pacific, also called transients, simulating the presence of potential predators. During winter, sympatric humpback whales and HFKWs both exploit the herring (Clupea harengus) stock which often overwinters in fjords in northern Norway (Huse et al. 2010). Mixed-species feeding aggregations are common and seem to be initiated more often by killer whales (Jourdain \& Vongraven 2017). The feeding sounds of HFKWs during winter could signal the presence of a food patch to eavesdropping hump- back whales. Marine MEKWs appear to exert a strong predation pressure on humpback whales, mainly targeting calves and juveniles (e.g. FlórezGonzález et al. 1994, Naessig \& Lanyon 2004, McCordic et al. 2014). Even though humpback whales in Norway are unlikely to be familiar with Northeast Pacific killer whales, we expected humpback whales to perceive these unfamiliar killer whales as threatening (like Curé et al. 2019). Humpback whales appear to be fight strategists (Ford \& Reeves 2008), and in many areas, they have been documented to actively approach MEKWs, possibly for mobbing or predator inspection (reviewed by Pitman et al. 2017). However, no such observation in the Northeast Atlantic was reported by Pitman and colleagues. Moreover, anti-predator responses could be graded in successive steps: first, an avoidance response, if the prey has detected the predator but the predator has not detected the prey yet (this is the context we simulate in our playback experiments), and a physical defence behaviour later, during the chase or the attack by the predator. We therefore expected an avoidance response to MEKW sounds rather than an approach.

We conducted killer whale playbacks in the fjords during winter (both HFKW and MEKW sounds) and offshore during summer (only MEKW sounds). In addition to killer whale ecotype, the ecological context of the playback experiments is another factor which could have influenced the behavioural responses of humpback whales to killer whale sounds.

\section{MATERIALS AND METHODS}

\subsection{Data collection}

We combined archival tag data and visual observations of tagged individuals at the surface to record the behaviour and movements of humpback whales before, during, and after playbacks of killer whale sounds. During each experiment, 1 humpback whale was tagged and identified as the focal individual (Altmann 1974). In 2011 and 2012, we deployed version 2 Dtags (Johnson \& Tyack 2003), and in 2016, we deployed version 3 Dtags. Dtags contain a suite of sensors $(250 \mathrm{~Hz} 3$-axis accelerometer, $250 \mathrm{~Hz} 3$-axis magnetometer, $50 \mathrm{~Hz}$ pressure sensor) and 2 hydrophones (sampling frequency: $96 \mathrm{kHz}$, sampling width: 16 bits). In 2017, we used 'mixed tags', a version 3 Dtag sensor suite in a custom-made housing which includes a GPS logger (FastLoc ${ }^{\mathrm{TM}}$, SirTrack, Wildlife Tracking Solutions). 
We attached all tags to the animals temporarily with suction cups using a long pole or a pneumatic launching system (ARTSTM, LKARTS). Humpback whales only showed short-term reactions - flinches and submersions - to tag deployments. All tags were equipped with a VHF beacon, which allowed identification of the focal whale at the surface for visual tracking and recovery of the tag after its detachment from the focal whale.

We started visually tracking the focal whale immediately after tagging. We recorded the position (based on range and bearing from the observation vessel) and heading of the focal whale when it was at the surface. We made an average of 1 observation every $4.89 \pm 1.86 \mathrm{~min}$ (mean $\pm \mathrm{SD}$; range 2.81-11.25 min). We made all visual tracking records in Logger 2010 (courtesy of the International Fund for Animal Welfare, Yarmouth, MA, USA).

\subsection{Playback procedure}

In June and July 2011 and 2012, we performed $\mathrm{N}=8$ playback experiments with MEKW sounds on summer feeding grounds off Spitsbergen, Norway (Table 1). In January 2016 and 2017, we conducted playback experiments with HFKW sounds $(\mathrm{N}=6)$ and MEKW sounds $(\mathrm{N}=4)$ in the fjords around Vengsøya, Norway (Table 1). The inshore-winter experiments were conducted specifically for this study, while offshore-summer experiments were initially conducted to investigate the responses of humpback whales to the playback of MEKW sounds as the main topic of a previous publication (Curé et al. 2015). The same experimental protocol was applied for summer and winter experiments, thus making the results directly comparable across seasons. The comparative framework of the present study justified the inclusion of the Curé et al. (2015) dataset in our analysis.

The 2011 and 2012 killer whale playbacks were conducted after the focal humpback whales had been exposed to naval sonar signals as part of a parallel project (detailed by Kvadsheim et al. 2015). The 2016 and 2017 fieldwork campaigns only included killer whale playback experiments and control noise broadcasts. In 2016 and 2017, we waited on average $1 \mathrm{~h} 34 \mathrm{~min} 37 \mathrm{~s} \pm 25 \mathrm{~min} 26 \mathrm{~s}$ (range $1 \mathrm{~h} 9 \mathrm{~min}$ $22 \mathrm{~s}-2 \mathrm{~h} 27 \mathrm{~min} 3 \mathrm{~s}$ ) from the tag deployment to the first playback. In 2011 and 2012, an average recovery period of $2 \mathrm{~h} 3 \mathrm{~min} 12 \mathrm{~s} \pm 1 \mathrm{~h} 10 \mathrm{~min} 2 \mathrm{~s}$ (range

Table 1. Overview of playback experiments and focal humpback whales. Each focal individual was given an 8-symbol identifier in the form aaBB_CCCd, where aa are the first initials of the genus and species, BB are the last 2 digits of the experiment year, CCC is the Julian date of the experiment, and d is the number of the tag deployment within the day from a to $\mathrm{z}$. We prepared several versions of each stimulus to reduce pseudoreplication (version column). For 2 individuals (mn11_160a and mn16_020a), the tag came off prematurely, and the post-exposure observation phase of the second experiment was not completed. In 1 case (mn16_018a), we were not able to retrieve the tag after the experiments, which restricted our data to the visual tracking information for this individual. We exposed some of the humpback whales to a broadband noise stimulus as a negative control. The whales barely reacted to it (Table S1 in Supplement 1 at www.int-res.com/articles/suppl/m660p217 supp1.xlsx), ensuring that the whales did not respond to unspecific sound broadcast by the speaker. MEKW: unfamiliar mammal-eating killer whale sounds; HFKW: familiar herring-feeding killer whale sounds; NOISE: broadband noise control. For a more detailed version of this table, including the timing of the killer whale playbacks and sonar exposure experiments, see Table S2 in Supplement 1

\begin{tabular}{|c|c|c|c|c|}
\hline $\begin{array}{l}\text { Individual } \\
\text { ID }\end{array}$ & $\begin{array}{l}\text { Study } \\
\text { location }\end{array}$ & $\begin{array}{l}\text { Ecological } \\
\text { context }\end{array}$ & $\begin{array}{c}\text { Sound } \\
\text { stimulus type }\end{array}$ & Version \\
\hline mn11_157a & Spitsbergen & $\begin{array}{l}\text { Offshore-summer } \\
\text { Offshore-summer }\end{array}$ & $\begin{array}{l}\text { MEKW } \\
\text { NOISE }\end{array}$ & v1 \\
\hline mn11_160a & Spitsbergen & $\begin{array}{l}\text { Offshore-summer } \\
\text { Offshore-summer }\end{array}$ & $\begin{array}{l}\text { MEKW } \\
\text { NOISE }\end{array}$ & $\mathrm{v} 2$ \\
\hline mn11_165e & Spitsbergen & $\begin{array}{l}\text { Offshore-summer } \\
\text { Offshore-summer }\end{array}$ & $\begin{array}{l}\text { MEKW } \\
\text { NOISE }\end{array}$ & v3 \\
\hline mn12_161a & Spitsbergen & $\begin{array}{l}\text { Offshore-summer } \\
\text { Offshore-summer }\end{array}$ & $\begin{array}{l}\text { NOISE } \\
\text { MEKW }\end{array}$ & v1 \\
\hline mn12_164b & Spitsbergen & $\begin{array}{l}\text { Offshore-summer } \\
\text { Offshore-summer }\end{array}$ & $\begin{array}{l}\text { NOISE } \\
\text { MEKW }\end{array}$ & v2 \\
\hline mn12_170a & Spitsbergen & $\begin{array}{l}\text { Offshore-summer } \\
\text { Offshore-summer }\end{array}$ & $\begin{array}{l}\text { NOISE } \\
\text { MEKW }\end{array}$ & v3 \\
\hline mn12_171a & Spitsbergen & $\begin{array}{l}\text { Offshore-summer } \\
\text { Offshore-summer }\end{array}$ & $\begin{array}{l}\text { MEKW } \\
\text { NOISE }\end{array}$ & $\mathrm{v} 1$ \\
\hline mn12_180a & Spitsbergen & $\begin{array}{l}\text { Offshore-summer } \\
\text { Offshore-summer }\end{array}$ & $\begin{array}{l}\text { NOISE } \\
\text { MEKW }\end{array}$ & v2 \\
\hline mn16_018a & Vengsøya & $\begin{array}{l}\text { Inshore-winter } \\
\text { Inshore-winter }\end{array}$ & $\begin{array}{l}\text { HFKW } \\
\text { NOISE }\end{array}$ & $\mathrm{v} 2$ \\
\hline mn16_020a & Vengsøya & $\begin{array}{l}\text { Inshore-winter } \\
\text { Inshore-winter }\end{array}$ & $\begin{array}{l}\text { MEKW } \\
\text { HFKW }\end{array}$ & $\begin{array}{l}\text { v1 } \\
\text { v3 }\end{array}$ \\
\hline mn16_023a & Vengsøya & $\begin{array}{l}\text { Inshore-winter } \\
\text { Inshore-winter }\end{array}$ & $\begin{array}{l}\text { HFKW } \\
\text { MEKW }\end{array}$ & $\begin{array}{l}\text { v3 } \\
\text { v1 }\end{array}$ \\
\hline mn16_024a & Vengsøya & $\begin{array}{l}\text { Inshore-winter } \\
\text { Inshore-winter }\end{array}$ & $\begin{array}{l}\text { NOISE } \\
\text { HFKW }\end{array}$ & v1 \\
\hline mn17_024a & Vengsøya & $\begin{array}{l}\text { Inshore-winter } \\
\text { Inshore-winter }\end{array}$ & $\begin{array}{l}\text { MEKW } \\
\text { HFKW }\end{array}$ & $\begin{array}{l}\text { v2 } \\
\text { v2 }\end{array}$ \\
\hline mn17_026a & Vengsøya & $\begin{array}{l}\text { Inshore-winter } \\
\text { Inshore-winter }\end{array}$ & $\begin{array}{l}\text { HFKW } \\
\text { MEKW }\end{array}$ & $\begin{array}{l}\text { v1 } \\
\text { v3 }\end{array}$ \\
\hline
\end{tabular}


39 min-3 h 39 min) separated sonar exposures and playback experiments.

The stimuli we used for playback experiments were natural sound sequences of feeding free-ranging killer whales, previously recorded with Dtags (Miller et al. 2010). We used 2 stimulus types: HFKW sounds recorded in Norway from killer whales feeding on herring and MEKW sounds recorded in southeastern Alaska from killer whales harassing and feeding on marine mammal prey. Noisy sound sections, such as flow noise from whale movements, bubbling, and surfacing noise, were removed from the stimuli. The resulting files were looped to $15 \mathrm{~min}$ and amplified to reach an average of 140 to $155 \mathrm{~dB}$ re $1 \mu \mathrm{Pa} @ 1 \mathrm{~m}$ for killer whale calls (similar to natural source levels, Miller 2006). We prepared 3 versions of each stimulus type from different recordings to reduce pseudoreplication (Table 1).

We presented MEKW sounds in 2 different contexts, offshore during early summer (beginning of the feeding season) and inshore during winter (end of the feeding season). HFKW sounds were only presented inshore during winter. We therefore had 3 combinations of stimulus type and context of presentation: MEKW sounds presented offshore during summer (OMEKW: offshore-summer MEKW) and inshore during winter (IMEKW: inshore-winter MEKW) and HFKW sounds presented inshore during winter (IHFKW: inshore-winter HFKW).

Each playback experiment consisted of three 15 min long periods: the pre-exposure observation period, the exposure period during which the stimulus was presented, and the post-exposure observation period. In the inshore-winter setting, we exposed 4 whales to 2 successive playback experiments - one with MEKW sounds and the other with HFKW sounds (Table 1). The order of stimulus presentation was alternated (Table 1). The average duration between successive experiments was $16 \mathrm{~min}$ $37 \mathrm{~s}$, which means that the time between the start of successive broadcasts was $46 \mathrm{~min} 37 \mathrm{~s}$ on average (range: $29 \min 16 \mathrm{~s}-1$ h 6 min $29 \mathrm{~s}$ ). On 2 occasions, the tag came off prematurely, and the post-exposure observation phase of the second experiment was incomplete (Table 1).

We used 2 boats during the playback experiments: one was devoted to tag deployment and visual tracking of the focal whale (the tracking boat, an 8.2 $\mathrm{m}$ steel hull vessel with inboard diesel engine propulsion), and the second was used for sound playbacks (the playback boat, a SeaBoy 705 MC aluminium hull vessel with an outboard Suzuki DF200 engine). The tracking boat continued to track the focal whale consistently irrespective of the playback timeline, and sightings of the tagged focal whale were used to position the playback boat. We aimed to place the playback boat ahead of the whale, slightly to the side of its path, so that either attraction or avoidance reactions could be clearly identified. The average distance between the focal whale and the sound source at the onset of the playbacks was $842 \pm 605 \mathrm{~m}$ (range 231-2915 m, see Table S1 in Supplement 1 at www.int-res.com/ articles/suppl/m660p217_supp1.xlsx). The position of the playback boat throughout the playback experiments is illustrated in Fig. S1a-zb in Supplement 2 at www.int-res.com/articles/suppl/m660p217_supp2. pdf. We calculated the estimated received levels of the stimulus at the start of the broadcast using the source level of the stimulus and the transmission loss formula provided by Wensveen (2012). They ranged from 86 to $102 \mathrm{~dB}$ re $1 \mu \mathrm{Pa}$ (Table S3). Most whales showed clear horizontal responses to the playback stimuli (either approach or avoidance), indicating that they could detect the broadcasts.

The playback chain consisted of a player (2011, 2012: Micro Track II recorder, M-Audio; 2016, 2017 : DR40 recorder, Tascam), an amplifier (2011, 2012: Z8000 amplifier, Cadence Sound; 2016, 2017: XMN502 amplifier, Sony), and a loudspeaker (2011, 2012: LL9642T loudspeaker, Lubell, frequency range $0.2-20 \mathrm{kHz} ; 2016,2017$ : LL9162T loudspeaker, Lubell, frequency range $0.2-20 \mathrm{kHz}$ ) with a supplied resistor. The playback boat moved into position before the pre-exposure period ended, turned its engine off, and lowered the loudspeaker $8 \mathrm{~m}$ underwater.

\subsection{Data treatment and response variables}

To test our hypotheses that humpback whales would approach the source of HFKW sounds and avoid the source of MEKW sounds, we computed the horizontal tracks of the focal whale during the playback experiments. We followed the method described by Wensveen et al. (2015) to construct the horizontal track of focal whales, which consists of a dead-reckoning track anchored to visual positions (and GPS fixes when available). We had no tag data for whale mn16_018a (Table 1), so we constructed the horizontal track of this whale with linear interpolation between visual surfacing positions and times. We quantified the approach or avoidance response of humpback whales by calculating a horizontal reaction score (HRS) for each playback. 


$$
\mathrm{HRS}_{t}=\frac{\text { Extrapolated distance }_{t}-\text { Real distance }}{t}
$$

HRSs measure the difference, relative to the sound source, between the actual position of the focal whale and its extrapolated position based on its movement patterns during the pre-exposure period. Extrapolated distance $e_{t}$ is the distance between the extrapolated position of the whale and the sound source at time $t$, real distance $t_{t}$ is the distance between the whale and the sound source at time $t$, and initial distance is the distance between the whale and the sound source at the onset of the playback (Fig. 1).

To calculate the extrapolated distance, we converted the latitude and longitude of the whale to UTM coordinates and made a linear regression between the whale's northing and easting during the preexposure period to get the whale's global heading. Next, we projected the positions of the whale at the start and at the end of the pre-exposure period on the regression axis to obtain the global distance travelled along the regression axis during the pre-exposure period (and thus its global speed). We used the global heading and speed of the whale during the preexposure period to extrapolate its position if it had kept the same movement patterns as during the pre-

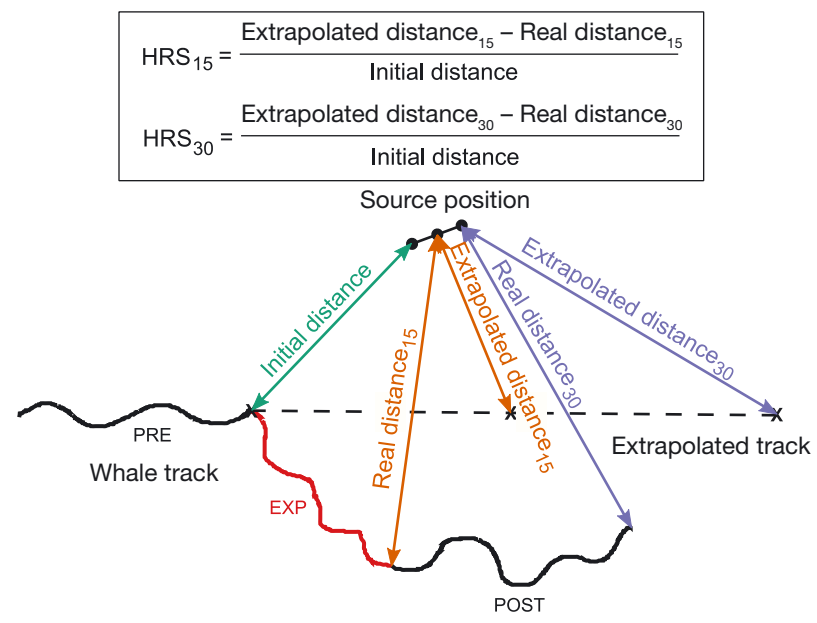

Fig. 1. Calculation of horizontal reaction scores (HRSs) from the track of the focal whale. HRSs measure the difference in the distance between the whale and the sound source and the distance expected if the whale had continued the same movement patterns (heading and speed) as during the preexposure period (PRE). The $\mathrm{HRS}_{15}$ quantifies the horizontal response during the playback. We used the $\mathrm{HRS}_{30}$ to determine whether behavioural responses extended into the post-exposure period (POST). EXP: exposure period during which the stimulus was presented exposure period. The extrapolated distance is measured between the extrapolated position of the whale and the position of the sound source. HRSs are positive values if real distance was smaller than extrapolated distance, which means that the whale approached the sound source relative to its prior movement trajectory, and are negative values if the focal whale avoided the sound source relative to its prior movement trajectory. We measured HRSs at the end of the broadcast (15 min, noted $\mathrm{HRS}_{15}$ ) to measure the whale's response during playback.

We measured additional variables to describe more fully the horizontal and vertical components of the humpback whales' behaviour. We selected 8 response variables in addition to the $\mathrm{HRS}_{15}$ described above. The horizontal response variables were the $\mathrm{HRS}_{15}$, the $\mathrm{HRS}_{30}$ (measured at the end of the postexposure period: Fig. 1), the approach index (AI), and the straightness index (SI).

$$
\mathrm{AI}=\frac{\text { Closest distance to sound source }}{\text { Initial distance to sound source }}
$$

AI measures the closest approach of the whale to the sound source during the exposure. AI values fall between 0 and 1 , with 0 meaning the whale came into contact with the source (strong approach) and 1 meaning the initial distance to the source was also the smallest (immediate avoidance). The AI compliments the HRS value, as it quantifies the maximum approach observed over the entire exposure period.

$$
\mathrm{SI}=\frac{\begin{array}{c}
\text { Distance between start and } \\
\text { end of experimental phase }
\end{array}}{\text { Total distance travelled }}
$$

SI measures the directedness of the whale's course (Batschelet 1981). SI values range from 1 if the whale travelled in a straight line to 0 if it turned in a circle.

We calibrated the pressure sensor data of the tags to compute dive profiles for the focal whales, from which we measured the vertical response variables. We defined a dive as any duration spent deeper than $5 \mathrm{~m}$. We selected this threshold based on the size of the humpback whales and the position of the tags; if the tag reached $5 \mathrm{~m}$ underwater, the focal whale was most likely diving. We described the vertical component of the responses with the maximum dive depth and maximum dive duration reached during each experimental period. We used maxima for dive depth and dive duration because the low number of dives within each experimental period (15 min) reduced the efficiency of descriptive statistics such as mean and median and because we judged that maxima would be efficient at detecting outlier response 
dives, such as exploration dives or vertical avoidance dives. For dives which overlapped experimental periods, we only took into account the portion of the dive within each given experimental period.

We calculated differences in SI, maximal dive duration, and maximal dive depth between experimental periods: between the playback period and the pre-exposure period to identify the responses of the whale during the stimulus presentation (noted 'variable PRE-EXP') $_{\text {' }}$ and between the post- and preexposure periods to determine whether the responses extended after the end of the broadcast (noted 'variable PRE-POST'). $^{\prime}$.

\subsection{Statistical analysis}

First, we performed a Kruskal-Wallis test to determine whether the behavioural responses of humpback whales to killer whale playbacks varied according to killer whale ecotype (either HFKW or MEKW) and context of presentation (either inshore during winter or offshore during summer). We pursued the analysis with a Bonferroni-corrected Dunn's procedure to identify significant pairwise differences in the responses to the playback between experimental conditions.

Ten of the 14 whales were subjected to only HFKW or MEKW sounds. We considered successive exposures to HFKW or MEKW sounds to the remaining 4 individuals as being independent samples in the Kruskal-Wallis test, after we visually verified the absence of a strong correlation between the behavioural response to successive experiments with the same individual and the lack of any consistent order effect. This allowed the inclusion of unpaired inshore-winter experiments (for whales which were exposed to noise broadcasts) and offshore-summer experiments, which were conducted on different individuals. Moreover, the time interval between successive playbacks to the same individual $(1 \mathrm{~h} 17 \mathrm{~s}$ \pm 7 min $9 \mathrm{~s}$ ) was at minimum 3.3 times longer than the playback itself. Therefore, these focal humpback whales likely had the necessary time to engage in further activities after the end of the playback, limiting the degree to which the independence assumption may be violated.

We tested whether the differences in the behavioural responses of humpback whales to the different experiment types were large and consistent enough for a classifier to correctly assign the experiment type-inshore-winter HFKW, inshorewinter MEKW, or offshore-summer MEKW - to a playback from the response variable data. This classification approach included additional aspects of the humpback whales' behaviour (e.g. diving behaviour). It provided a more integrated description of the responses of humpback whales to the different playbacks. We used the random forest procedure (Breiman 2001). The random forest combines the output of multiple tree classifiers. Each individual tree was trained on a random subset of 4 inshore-winter HFKW, 3 inshore-winter MEKW, and 5 offshore-summer MEKW experiments (roughly two-thirds of each experiment type) and classified the remaining third. For each sample, the random forest outcome was the majority vote of all trees which did not have this sample in their training set. We used median values for whales with missing tag data and incomplete experiments (Table 1, Table S1).

The accuracy of the random forest depends on 3 main parameters: the number of trees, the size of the subset of variables selected to split each node during training, and the depth of the trees. We chose an arbitrarily large number of trees (100000) because accuracy tends to increase with tree number and because our low sample size made computational costs negligible. We selected 3 variables to split each node. Our choice was guided by the total number of measured variables but reduced compared to standard formulas (e.g. Latinne et al. 2001, Cutler et al. 2007) to increase accuracy (as advised by Breiman 2001). As we were aiming to classify playbacks according to 3 experimental conditions, we constructed the simplest tree classifiers, with 2 splits resulting in 3 terminal nodes, each of which corresponded to 1 experimental condition.

In addition to classification, the random forest provides the possibility to assess the importance of each variable in the decision process. We did so by randomly permuting the values of each variable and computing the resulting reduction in accuracy of the classifier. We centred and scaled all variables before running the random forest to avoid size effects in the classification or the calculation of variable importance (Strobl et al. 2008). We used the 3 most important variables to build a 3-dimensional graphical representation of the behavioural responses to playback.

We used MATLAB R2017a (MathWorks) to calibrate tag data, compute dive profiles and horizontal tracks, and draw the 3-dimensional plot. We used $\mathrm{R}$ v.3.4.1 (R Core Team 2017) to run the random forests with the 'randomForest' package (Liaw \& Wiener 2002) and the Dunn's procedure with the 'dunn.test' package v.1.3.5 (Dinno 2017). 


\subsection{Ethical note}

Tagging activities were licenced under permits issued by the Norwegian Animal Research Authority (2011-2012, permit no. S-2011/38782) and the Norwegian Food Health Authority (2016-2017, permit ID 8165). The research protocol was approved by the Animal Welfare Ethics Committee of the University of Saint Andrews.

\section{RESULTS}

\subsection{Horizontal approach and avoidance responses to killer whale playback}

The horizontal responses of humpback whales to killer whale playbacks varied according to the combination of killer whale ecotype and context of presentation (Kruskal-Wallis test: $H=5.1711, \mathrm{p}=0.075$ ). This p-value of 0.075 means that under the assumption that humpback whales respond similarly to IMEKW, OMEKW, and IHFKW playbacks (our null hypothesis), there would only be a $7.5 \%$ chance to observe a difference in horizontal response across experiment types as large as the one we report. Specifically, responses to HFKW sounds inshore during winter differed from responses to MEKW sounds offshore during summer (Bonferroni-corrected Dunn's procedure: $Q=2.2111, \mathrm{p}=0.0405)$. Humpback whales approached the source of HFKW sounds inshore during winter (5 of 6 experiments, Fig. 2), whereas they strongly avoided the source of MEKW sounds offshore during summer ( 7 of 8 experiments, Fig. 2). The horizontal responses to MEKW sounds inshore during winter were more variable, with 2 approaches and 2 avoidances (Fig. 2). They did not significantly differ from either responses to HFKW sounds inshore during winter $(Q=1.5235, \mathrm{p}=0.192)$ or responses to MEKW sounds offshore during summer $(Q=0.3441$, $\mathrm{p}=1$ ). The horizontal tracks and dive profile of the focal whales during playback experiments are presented in Figs. S1 \& S2, respectively.

One playback of MEKW sounds offshore during summer resulted in a large positive HRS, corresponding to an unusually strong horizontal approach (Fig. 2). Closer inspection of the horizontal track (Fig. S1c) and dive profile (Fig. S2c) of this particular whale indicated that it was deep diving during the pre-exposure period and stayed in the same area at the surface during the playback. The HRS of this experiment was 2.5 times larger than a directed approach reaching the sound source (Table S1,

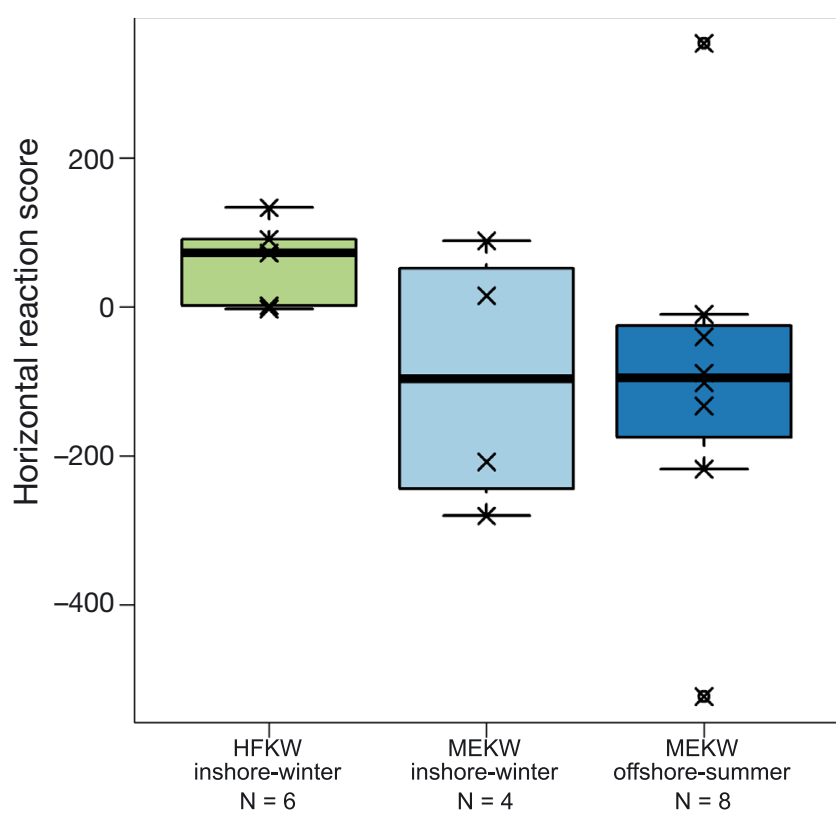

Fig. 2. Horizontal response of humpback whales to playback of killer whales according to experimental conditions. Boxplot of the horizontal reaction score (HRS) to playback of herring-feeding killer whale (HFKW) sounds (inshore-winter only: $N=6$ ) and mammal-eating killer whale (MEKW) sounds (both inshore-winter: $\mathrm{N}=4$, and offshore-summer: $\mathrm{N}=8$ ). X-crosses represent individual experiments. Circles mark experiments falling outside the whiskers. Boxes cover the interquartile range, and whiskers cover all data points within 2 interquartile ranges from the median. Positive HRSs correspond to approaches of the sound source, and negative HRSs correspond to avoidances of the sound source. Horizontal tracks and dive profiles of individual whales during the playback experiments are available in Figs. S1 \& S2 in Supplement 2, respectively

Fig. S1t). This case highlights the limitations of the HRS method: large contrasts in behaviour between the pre-exposure and exposure periods may drive the value of the HRS, irrespective of the behaviour relative to the sound source. We therefore assessed the analysis results if we removed this experiment as an outlier. As expected, discarding this outlier greatly reduced the statistical uncertainty of the difference in behavioural response across the different playback types (general comparison: $H=8.0798$, $p=0.018$; OMEKW vs. IHFKW: $Q=2.8221, \mathrm{p}=0.007$; OMEKW vs. IMEKW: $Q=0.8463, \mathrm{p}=0.569$ ). Note that we retained this outlier for all subsequent analyses.

\subsection{Horizontal and vertical components of behavioural responses to killer whale playback}

The random forest analysis, used to further investigate the horizontal and vertical component of the 
behavioural responses to the playbacks, correctly classified $100 \%$ of inshore-winter HFKW playbacks, $62.5 \%$ of offshore-summer MEKW playbacks, and $50 \%$ of inshore-winter HFKW playbacks (Table 2). Taking into account the sample sizes of the different playback types, the classifier achieved an overall accuracy of $78.3 \%$ (Table 2 ).

The most important variable for the random forest classification was the $\mathrm{HRS}_{15}$ (Fig. 3A). Indeed, HRS 15 values were mostly positive (5 of 6 ) for inshorewinter HFKW playbacks, mostly negative (7 of 8) for offshore-summer MEKW playbacks, and variable for inshore-winter MEKW playbacks (Fig. 2).

The second and third most important variables for the random forest classification were the differences in maximum dive duration and maximum dive depth between the post-exposure and the pre-exposure periods (respectively maximum dive duration $_{\text {PRE-POST }}$ and maximum dive depth PRE-POST: $_{\text {: }}$ Fig. 3A). Humpback whales performed deeper and longer dives during inshore-winter HFKW playbacks but were mostly back to preexposure dive duration and depth levels as soon as the broadcast ended (Fig. 4D), whereas maximum dive duration tended to increase during inshore-winter MEKW playbacks and to further increase after the end of the broadcast (Fig. 4D). Maximum dive duration PRE-POST $_{\text {and }}$ maximum dive depth PRE-POST $_{\text {were }}$ more variable for offshore-summer experiments (Fig. 4D,E).

Other response variables were less informative and thus had only a marginal influence on classification performance (Fig. 3A). Horizontal responses over both the exposure and the post-exposure periods $\left(\mathrm{HRS}_{30}\right)$ followed the same general trends as horizontal responses during the broadcast $\left(\mathrm{HRS}_{15}\right)$ but were much more variable (Fig. 4A). The SI of the whale tracks tended to decrease in response to all experiment types and covered large ranges (Fig. 4C). The maximum dive depth and duration between the pre-exposure period and the broadcast period tended to increase in response to inshore-winter playbacks of HFKW and MEKW sounds and were variable in response to offshore- summer playbacks of MEKW sounds. However, they covered large ranges in all 3 experiment types (Fig. 4D,E). Moreover, while the $\mathrm{AI}$ in response to some inshore-winter HFKW playbacks was very small

Table 2. Random forest classification of playback experiments according to killer whale ecotype and ecological context. IHFKW: inshore-winter playback of herring-feeding killer whale sounds; IMEKW: inshore-winter playback of mammal-eating killer whale sounds; OMEKW: offshoresummer playback of mammal-eating killer whale sounds

\begin{tabular}{|c|c|c|c|c|}
\hline \multirow{2}{*}{$\begin{array}{l}\text { Playback } \\
\text { type }\end{array}$} & \multicolumn{3}{|c|}{ —Classification outcome - } & \multirow{2}{*}{$\begin{array}{c}\text { Accuracy } \\
(\%)\end{array}$} \\
\hline & IHFKW & IMEKW & OMEKW & \\
\hline IHFKW & 6 & 0 & 0 & 100 \\
\hline IMEKW & 1 & 2 & 1 & 50 \\
\hline \multirow[t]{2}{*}{ OMEKW } & 2 & 1 & 5 & 62.5 \\
\hline & \multicolumn{3}{|c|}{$\begin{array}{c}\text { Overall accuracy } \\
\text { (balanced) }\end{array}$} & 78.3 \\
\hline
\end{tabular}

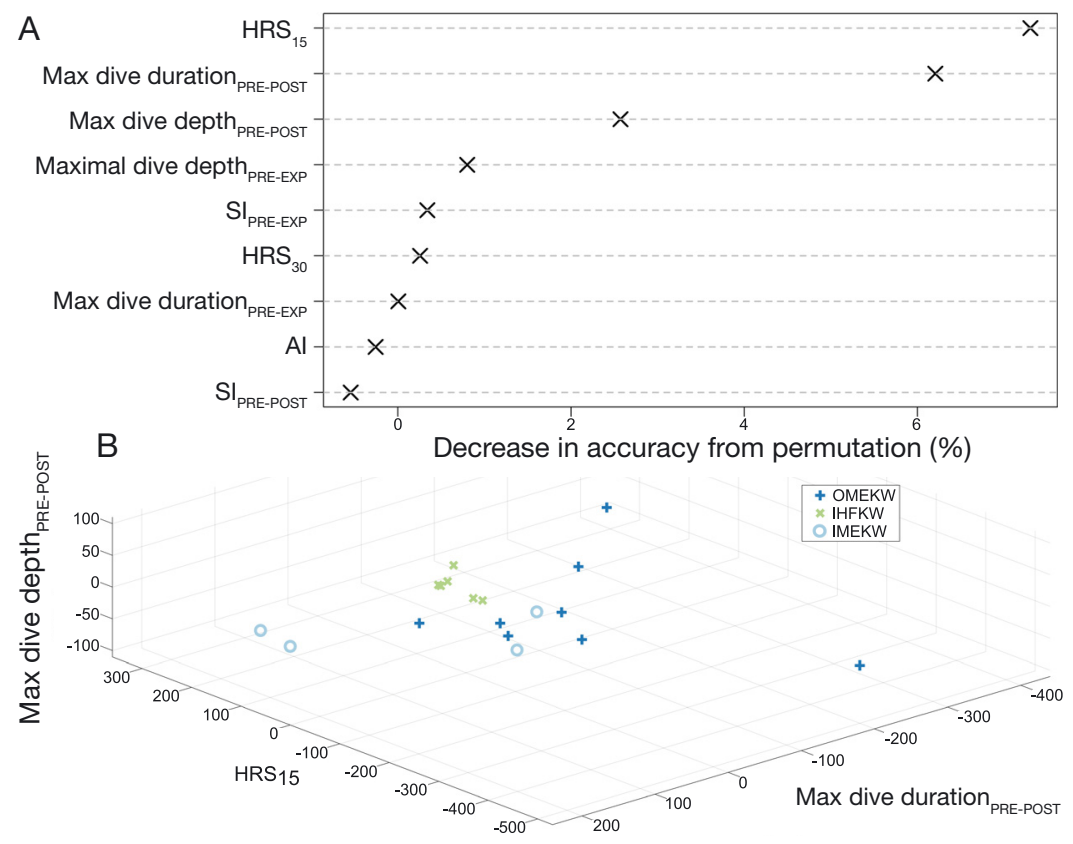

Fig. 3. Variable importance and visualisation of the random forest classification results. (A) Importance of each response variable in the random forest classification. Variable importance was measured as the mean decrease in accuracy resulting from the random permutation of the values of each given response variable. The 3 most important variables were the horizontal response during the broadcast $\left(\mathrm{HRS}_{15}\right)$, the difference in maximum dive duration between

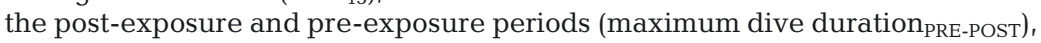
and the difference in maximum dive depth between the post-exposure and pre-

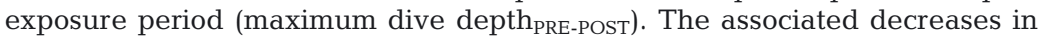
accuracy were respectively $7.4,6.2$, and $2.5 \%$. HRS: horizontal reaction score; SI: straightness index; AI: approach index. (B) Behavioural responses to killer whale playback according to ecotype and context of presentation described by the 3 most important variables in the random forest classification. IHFKW: inshore-winter herring-feeding killer whale playbacks; IMEKW: inshore-winter mammal-eating killer whale playbacks; OMEKW: offshore-summer mammaleating killer whale playbacks 

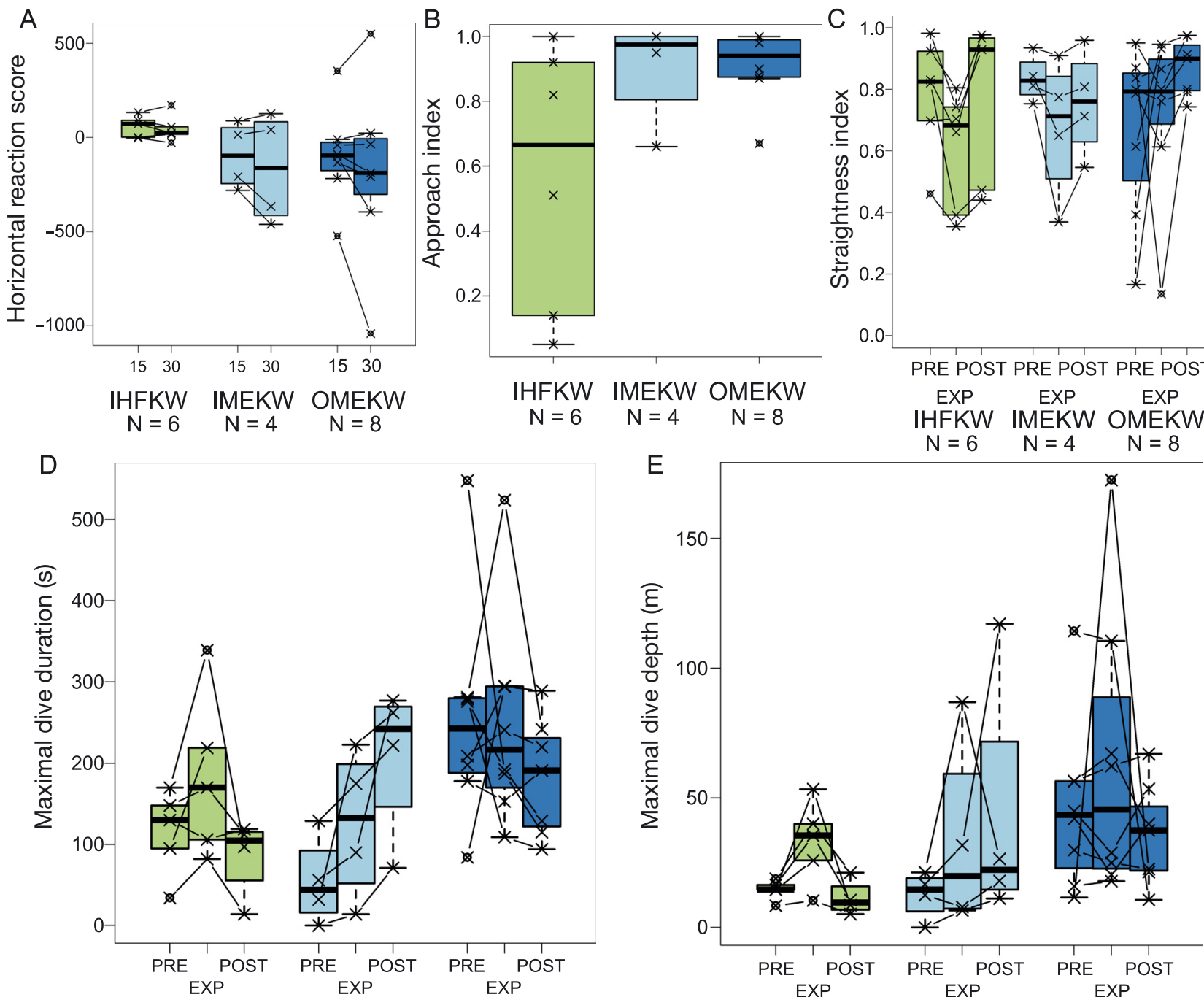

PRE POST PRE POST PRE POST
EXP $\quad$ EXP IHFKW IMEKW OMEKW $\mathrm{N}=6 \quad \mathrm{~N}=4 \quad \mathrm{~N}=8$ $\mathrm{N}=6 \quad \mathrm{~N}=4 \quad \mathrm{~N}=8$

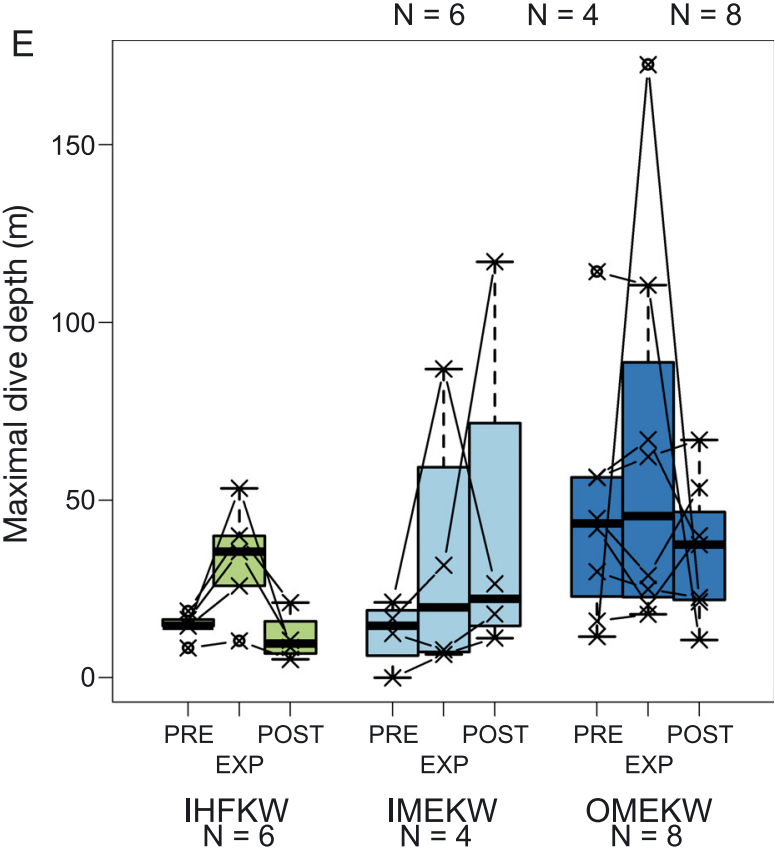

Fig. 4. Behavioural responses of humpback whales to playback of killer whale sounds. (A) Horizontal reaction score during the playback $\left(\mathrm{HRS}_{15}\right.$, labelled 15 on the figure) and after the end of the post-exposure period ( $\mathrm{HRS}_{30}$, labelled 30). Black lines link scores from the same playback session. Positive scores correspond to approaches toward the sound source, and negative scores correspond to avoidance thereof. The $\mathrm{HRS}_{30}$ followed the same trends as the $\mathrm{HRS}_{15}$ but covered larger ranges. Two playback experiments were missing the $\mathrm{HRS}_{30}$ due to premature detachment of the tag during the post-exposure period. (B) Approach index (AI). Small values of AI (close approaches of the sound source) were reported for inshore-winter herring-feeding killer whale experiments; however, large values of AI (immediate avoidance of the source source) were present in all 3 experimental conditions. (C) Straightness index (SI) during each experimental phase. Humpback whales reduced the directedness of their paths during the broadcasts in all experimental conditions; however, SI covered large ranges. (D) Maximal dive duration during each experimental phase. Maximal dive duration increased during inshore-winter herring-feeding killer whale playbacks and went back to pre-exposure levels after the broadcasts. Humpback whales dived for longer durations during and after inshore-winter mammal-eating killer whale playbacks. Maximal dive duration was variable throughout offshoresummer mammal-eating killer whale experiments. (E) Maximal dive depth during each experimental phase. Maximal dive depth followed the same trends as maximal dive depth. PRE: pre-exposure period; EXP: broadcast of the playback stimulus; POST: post-exposure period; IHFKW: inshore-winter herring-feeding killer whale playbacks; IMEKW: inshore-winter mammaleating killer whale playbacks; OMEKW: offshore-summer mammal-eating killer whale playbacks. Crosses represent individual experiments. Circles mark experiments falling outside the whiskers. Boxes cover the interquartile range, and whiskers cover all data points within 2 interquartile ranges from the median

(indicating close approaches of the sound source), we found a large AI for all 3 experiment types (Fig. 4B).
Numerical values of all response variables are listed in Table S1. 


\section{DISCUSSION}

Our results indicate that the behavioural responses exhibited by humpback whales to the playback of killer whale sounds differed according to the combination of killer whale ecotype and ecological context of presentation. Humpback whales horizontally approached the source of HFKW sounds and performed deeper and longer dives during the broadcasts. In contrast, the sounds of unfamiliar MEKWs triggered mostly horizontal avoidance responses. These differences in response suggest that humpback whales may be able to discriminate between the sounds of unfamiliar, potentially predatory killer whales and familiar killer whales feeding on the same prey.

Based on the output from the random forest classification, we were able to describe the typical behavioural responses of humpback whales to killer whale playback according to killer whale ecotype and ecological context. Specifically, humpback whales were strongly attracted to the sounds of HFKWs inshore during winter $\left(\mathrm{HRS}_{15}\right.$ : Fig. 4A; AI: Fig. 4B). This attraction exhibited during the playback typically did not last during the post-exposure period $\left(\mathrm{HRS}_{30}\right.$, Fig. 4A). Dive depth and duration were greater during such playbacks. These diving responses ceased as soon as the playback stopped (maximal dive duration and maximal dive depth: Fig. 4D,E). By comparison, 7 of 8 humpback whales showed strong avoidance away from the source of MEKW sounds offshore during summer $\left(\mathrm{HRS}_{15}\right.$ : Fig. 4A; AI: Fig. 4B). Some avoidance responses extended into the postexposure period $\left(\mathrm{HRS}_{30}\right.$ : Fig. $\left.4 \mathrm{~A}\right)$. The maximum dive duration and depth varied greatly across individuals (Fig. 4D,E). The behavioural responses of humpback whales to the playback of MEKW sounds inshore during winter were variable, with 2 strong avoidances and 2 approaches (HRS: Fig. 4A; AI: Fig. 4B). Humpback whales tended to dive deeper and for longer durations during such playbacks, and the increasing trend continued into the post-exposure period (maximum dive duration and depth: Fig. 4D,E).

The ability to discriminate between familiar and unfamiliar heterospecifics has been demonstrated in many terrestrial taxa, for instance in birds (e.g. Wascher et al. 2012) or primates (e.g. Candiotti et al. 2013). Moreover, the ability to associate discrete heterospecific calling behaviours with distinct ecological significance was also shown to be widespread in terrestrial animals (e.g. Fuong et al. 2014, Dawson Pell et al. 2018). Our results indicated the ability to discriminate between the sounds of 2 killer whale ecotypes in a baleen whale species, the humpback whale. Humpback whale calves and juveniles are particularly targeted by killer whale attacks (Naessig \& Lanyon 2004, Steiger et al. 2008, McCordic et al. 2014). Therefore, humpback whales may benefit from differentiating between predatory and nonpredatory killer whale ecotypes. The ability to discriminate between the sounds of different killer whale ecotypes has been demonstrated in a species of pinniped (Deecke et al. 2002) and in a species of odontocete (Curé et al. 2019). Our results, along with the results from Deecke and colleagues and Curé and collaborators, suggest that fine-scale acoustic discrimination abilities may be widespread among marine mammals. Given the importance of the acoustic channel for information transfer in the marine environment, marine mammals could eavesdrop on heterospecific sounds to adopt appropriate behaviours ahead of or during interspecific interactions.

Although humpback whales have been documented to approach MEKWs in several locations, this behaviour was never observed in the Northeast Atlantic (Pitman et al. 2017). Therefore, the 'approach and explore' responses of humpback whales to broadcasts of familiar HFKW sounds inshore during winter are more consistent with observations of humpback whales and HFKW feeding aggregations in the study area than with a predator inspection or mobbing behaviour in response to a perceived predator. Jourdain \& Vongraven (2017) observed that such mixed-species aggregations were most often initiated by killer whales and posited that killer whale feeding sounds may attract humpback whales; our results are consistent with this hypothesis.

The tendency of humpback whales to avoid the source of unfamiliar MEKW sounds is in line with the behaviours of other cetacean species interacting with killer whales (reviewed by Jefferson et al. 1991) or responding to killer whale sound playbacks (e.g. Deecke et al. 2002, Bowers et al. 2018, Curé et al. 2019). Our results indicate that unfamiliar MEKW sounds were likely perceived as a threat by humpback whales. Some cetacean species exhibit fight strategies when confronted with a predator, physically defending themselves or mobbing the attacker, whereas other species adopt flight responses to prevent predator encounters or to avoid an upcoming attack (Ford \& Reeves 2008). In addition, some species can exhibit different anti-predator strategies depending on context. Humpback whales are considered, from anatomical observations and documented encounters with killer whales, as a fight strategist species (Ford \& Reeves 2008, Pitman et al. 2017). 
However, as reported previously (Curé et al. 2015) and confirmed here, humpback whales can show flight responses away from a source broadcasting unfamiliar MEKW sounds, a context which simulates an early stage of an encounter with predatory killer whales which may not have detected the humpback whales yet.

The behavioural responses of humpback whales to familiar HFKW sounds were more correctly classified $(100 \%)$ than the responses to unfamiliar MEKW sounds, both inshore during winter $(50 \%)$ and offshore during summer $(62.5 \%)$. The possible 'dinnerbell' effect of familiar HFKW sounds was clearly identifiable: it consisted of a horizontal approach towards the sound source and an increase of dive depth and duration, potentially to explore the environment around it. However, anti-predator strategies likely vary depending on the internal state of the animals, the characteristics of their habitat, and the nature of the threat: behaviours may include horizontal or vertical avoidance, crypsis, or any combination of these strategies (Ford \& Reeves 2008). Therefore, the expected anti-predator responses to unfamiliar MEKW sounds may be less stereotyped than the approach responses expected during familiar HFKW playbacks and could be more difficult to recognise using the random forest.

Another striking difference between the behavioural responses of humpback whales to the sounds of familiar HFKWs and unfamiliar MEKWs was that the former only lasted to the end of the playback, whereas the latter tended to extend into the postexposure period. MEKWs are mostly silent when hunting and, until an attack is launched, most likely to avoid being detected by their acoustically sensitive prey (e.g. Guinet et al. 2000, Deecke et al. 2005, Jourdain et al. 2017). However, they commonly produce sounds after a kill and when consuming a prey (Deecke et al. 2005). Therefore, the cessation of MEKW sounds could indicate to prey species that nearby predators have started an active hunt, thus eliciting anti-predator behaviour in humpback whales. The dive depth and duration of humpback whales was higher after inshore-winter playbacks of MEKW sounds than during these broadcasts. Curé and colleagues also noted that 5 of 8 humpback whales off Spitsbergen (offshore-summer experiments in this study) increased their swimming speed during MEKW playbacks and further increased it when the playbacks ended (Curé et al. 2015).

The behavioural responses of humpback whales to the sounds of unfamiliar MEKWs seemed to be influenced by the ecological context in which we presen- ted the sounds. Humpback whales showed strong avoidance of MEKW sounds in 7 of 8 offshoresummer experiments. Compared with this clear response, humpback whales showed contrasted responses to the sounds of unfamiliar MEKWs inshore during winter: 2 whales approached the source of the sounds, and 2 other individuals swam away from it.

These contexts of presentation differed in topography and corresponded to different functional seasons for humpback whales. Although the fjords are not so narrow that they impede escape, the freedom of movement of humpback whales in fjords is reduced compared to the open sea. Moreover, several species of cetaceans, including humpback whales, were reported staying in kelp beds or in shallow areas during killer whale encounters (Ford \& Reeves 2008): such refuges may only be found in the inshore environment. Both the greater freedom of movement to escape and the absence of hiding places suggest that the avoidance response of humpback whales to killer whales may be stronger offshore. In addition, offshore humpback whales may not have experience feeding commensally with killer whales, compared to inshore humpback whales which routinely form mixed-species feeding aggregations with HFKWs (Jourdain \& Vongraven 2017). This difference in experience could explain why offshore humpback whales were less likely to approach the source of killer whale sounds (1 of 8 cases) than inshore humpback whales ( 7 of 10 cases). However, we have no information about the life history of the humpback whales we tagged during this study to verify this hypothesis. Another difference between the 2 contexts is that offshore humpback whales were exposed to naval sonar prior to the killer whale playbacks (Table S3). Sonar exposures may have sensitised the humpback whales or increased the likeliness of an avoidance response to the killer whale playbacks.

The experiments performed offshore during early summer were representative of a context in which humpback whales need to replenish their resources after a breeding season in tropical waters and a round-trip migration without feeding (Clapham \& Mead 1999). In contrast, January marks the end of the feeding season, and thus humpback whales were presumably in optimal body condition and most likely about to start their southward migration. The offshore-summer and inshore-winter situations may therefore correspond to different balances along the trade-off between foraging and escaping predation risk, which could explain why responses to MEKW sounds depended on context. Offshore during sum- 
mer, avoiding MEKWs means evading the risk of injury or death but losing the benefits of the current behaviour (mostly foraging: Sivle et al. 2015), while not avoiding them implies an increased predation risk but ensures the completion of the current activity. Inshore during winter, humpback whales reach the end of the feeding season: there is less pressure to forage, and humpback whales in optimal condition could be less vulnerable to predator encounters. The decision whether to avoid potential predators depends on both how vulnerable individuals are and how beneficial their current behaviour is. Similar trade-offs between foraging and predation risks have been described in bats (e.g. Arndt et al. 2018) or lizards (e.g. Cooper 2000).

Inshore during winter, humpback whales exposed to the playback of unfamiliar MEKW sounds showed contrasting responses: 2 individuals (mn16_020a and mn16_023a) approached the sound source, whereas 2 individuals (mn17_024a and mn17_026a) avoided it. There was no strong relationship between the behavioural responses to the stimulus and whether it was presented first or second (Table S1). Interestingly, both inshore-winter MEKW playbacks performed in 2016 resulted in approaches, whereas both 2017 experiments triggered avoidance responses. Some ecological variable may have changed from 2016 to 2017, which could explain the contrast in the humpback whale responses to our acoustic stimuli. Food availability could be a suitable candidate variable. If there was less herring in the fjords, humpback whales could have been in worse condition and therefore less likely to be able to fight killer whale attackers or sustain the costs of escaping. Unfamiliar MEKW sounds could then have elicited stronger avoidance responses. Alternatively, a fluctuating presence of local MEKWs in the fjords could result in avoidance responses of variable intensity through habituation or sensitisation. The ecology of marine MEKWs in the Northeast Atlantic is poorly known (Jourdain et al. 2017). However, some killer whales from this population were reported hunting seals and cetacean prey, such as porpoises and minke whales (de Bruyn et al. 2013). Therefore, it may be possible that humpback whales encounter both HFKWs and MEKWs from the study region within a short time span.

Over the course of this study, we selected the first whale we could tag as the focal individual. As a result, the humpback whales we monitored during playback experiments could have been a biased subset of the populations: individuals more likely to approach the experimental vessels or easier to tag, therefore possibly less adverse to disturbance in general. Our experimental protocol required the prolonged presence of a tracking boat close to the animals. However, the average distance between the focal whale and the tracking boat was $213.3 \pm$ $131.4 \mathrm{~m}$ and thus larger than the $100 \mathrm{~m}$ threshold for disturbance previously defined (e.g. Scheidat et al. 2004, Stamation et al. 2009). It is unlikely that the tracking boat greatly affected the responses of the focal whales to the playback stimuli. Moreover, given that the tracking boat was present before, during, and after the playback experiments, we assumed that the recorded behavioural responses were elicited by the sound stimuli presentation and not by the boat presence.

The initial distance between the sound source and the focal whale (Table S1) was set up to be closer than the likely distance over which humpback whales could have been able to detect killer whale sounds. The sudden occurrence of nearby killer whale sounds might have exacerbated the responses of humpback whales to the acoustic stimuli. However, killer whales are not constantly vocally active. Our protocol, simulating the presence of killer whales starting to vocalise several hundred meters from the humpback whales, mimicked a potential real scenario.

The humpback whales we monitored during this study were familiar with HFKW sounds (at least inshore during winter) but most likely unfamiliar with the MEKW sounds we used. Therefore, we could not establish whether humpback whales identified each ecotype or if they simply distinguished familiar from unfamiliar killer whales sounds. In a similar study, Deecke and colleagues concluded that harbour seals habituated selectively to local, non-threatening killer whales (Deecke et al. 2002). Additional experiments, using sounds of unfamiliar fish-eating killer whales or familiar MEKWs, are still needed before we can reach such a definitive conclusion.

Our study used acoustic recordings of natural sequences and hence was not designed to elucidate which sound features specifically enabled the humpback whales to discriminate between the 2 sound types. The major acoustic difference between HFKWs and MEKWs is that the former rely on echolocation clicks for foraging and display tail slap sounds as part of the herring-foraging strategy (Simon 2005), whereas the latter produce much fewer clicks and no tail slaps (Deecke et al. 2005). The presence of tail slaps or multiple echolocation clicks could signal to humpback whales if they are facing a group of HFKWs or MEKWs. Further playback experiments 
could provide more insight into the acoustic parameters likely to support the discrimination between the sounds of different killer whale ecotypes by other marine mammal species. Chimera stimuli, such as HFKW calls without echolocation clicks and tail slaps or MEKW calls associated with intense echolocation activity and tail slaps, could be used to determine whether echolocation activity and specific feeding sounds are crucial in the discrimination process.

It might also be that some specific parameters in MEKW sounds trigger anti-predator responses. Indeed, it was recently shown in other species exposed to the playback of MEKW sounds that the presence of call types containing non-linear phenomena in the stimuli induced strong anti-predator responses (Bowers et al. 2018). Moreover, HFKWs and MEKWs also differ in the characteristics of their calls, such as frequency modulation patterns (Deecke et al. 2005) or frequency (Filatova et al. 2015). Some parameters of the calling behaviour (e.g. call rate, overlapping calls) may be indicators of the size of the killer whale group or of the behaviour they are engaged in. Thus, the level of vocal activity of a killer whale group may be related to the level of threat they represent to humpback whales (Lima \& Dill 1990). Further research could identify differences across various acoustic parameters between the vocal production of different killer whale ecotypes or of killer whales engaged in different activities. These specific parameters may convey the information which helps eavesdroppers, such as humpback whales, to decide on which behaviour to adopt upon the detection of killer whale sounds.

Acknowledgements. This research has been part of the 3S (Sea mammals, Sonar, Safety) project funded by the US Office of Naval Research, the Royal Norwegian Navy, the Norwegian Ministry of Defence, the Defence Research and Development Department of the Netherlands Ministry of Defence, and the French Ministry of Defence (DGA). We thank all members of the fieldwork crew for their effort over the years. We are grateful to Dr. Valerie Dufour for her critical reading of the manuscript.

\section{LITERATURE CITED}

Altmann J (1974) Observational study of behavior: sampling methods. Behaviour 49:227-267

Arndt RJ, O'Keefe JM, Mitchell WA, Holmes JB, Lima SL (2018) Do predators influence the behaviour of temperate-zone bats? An analysis of competing models of roost emergence times. Anim Behav 145:161-170

Barrett-Lennard LG, Ford JKB, Heise KA (1996) The mixed blessing of echolocation: differences in sonar use by fisheating and mammal-eating killer whales. Anim Behav 51:553-565
Batschelet E (1981) Circular statistics in biology. Academic Press, New York, NY

Beattie MC, Moore PA (2018) Predator recognition of chemical cues in crayfish: diet and experience influence the ability to detect predation threats. Behaviour 155:505-530

* Bowers MT, Friedlaender AS, Janik VM, Nowacek DP, Quick NJ, Southall BL, Read AJ (2018) Selective reactions to different killer whale call categories in two delphinid species. J Exp Biol 221:jeb162479

* Breiman L (2001) Random forests. Mach Learn 45:5-32

* Candiotti A, Zuberbühler K, Lemasson A (2013) Voice discrimination in four primates. Behav Processes 99:67-72

* Clapham PJ, Mead JG (1999) Megaptera novaeangliae. Mamm Species 604:1-9

* Cooper W (2000) Tradeoffs between predation risk and feeding in a lizard, the brown-headed skink (Eumeces laticeps). Behaviour 137:1175-1189

Cummings WC, Thompson PO (1971) Gray whales, Eschrichtius robustus, avoid the underwater sounds of killer whales, Orcinus orca. Fish Bull 69:525-530

Curé C, Antunes R, Samarra F, Alves AC, Visser F, Kvadsheim PH, Miller PJO (2012) Pilot whales attracted to killer whale sounds: acoustically-mediated interspecific interactions in cetaceans. PLOS ONE 7:e52201

Curé C, Antunes R, Alves AC, Visser F, Kvadsheim PH, Miller PJO (2013) Responses of male sperm whales (Physeter macrocephalus) to killer whale sounds: implications for anti-predator strategies. Sci Rep 3:1579

Curé C, Sivle LD, Visser F, Wensveen PJ and others (2015) Predator sound playbacks reveal strong avoidance responses in a fight strategist baleen whale. Mar Ecol Prog Ser 526:267-282

* Curé C, Isojunno S, Vester HI, Visser F and others (2019) Evidence for discrimination between feeding sounds of familiar fish and unfamiliar mammal-eating killer whale ecotypes by long-finned pilot whales. Anim Cogn 22: 863-882

Cutler DR, Adwards TC, Beard KH, Cutler A, Hess KT, Gibson J, Lawlaer JJ (2007) Random forests for classification in ecology. Ecology 88:2783-2792

* Dawson Pell FSE, Potvin DA, Ratnayake CP, FernándezJuricic E, Magrath RD, Radford AN (2018) Birds orient their heads appropriately in response to functionally referential alarm calls of heterospecifics. Anim Behav 140: 109-118

de Bruyn PJN, Tosh CA, Terauds A (2013) Killer whale ecotypes: Is there a global model? Biol Rev Camb Philos Soc 88:62-80

* Deecke VB (2006) Studying marine mammal cognition in the wild: a review of four decades of playback experiments. Aquat Mamm 32:461-482

* Deecke VB, Slater PJB, Ford JKB (2002) Selective habituation shapes acoustic predator recognition in harbour seals. Nature 420:171-173

* Deecke VB, Ford JKB, Slater PJB (2005) The vocal behaviour of mammal-eating killer whales: communicating with costly calls. Anim Behav 69:395-405

Dinno A (2017) dunn.test: Dunn's test of multiple comparisons using rank sums. https://CRAN.R-project.org/ package $=$ dunn.test

* Ellison WT, Southall BL, Clark CW, Frankel AS (2012) A new context-based approach to assess marine mammal behavioral responses to anthropogenic sounds: marine mammal behavioral responses to sound. Conserv Biol 26: $21-28$ 
Emmering QC, Schmidt KA (2011) Nesting songbirds assess spatial heterogeneity of predatory chipmunks by eavesdropping on their vocalizations: eavesdropping on a nest predator. J Anim Ecol 80:1305-1312

Evans TA, Inta R, Lai JCS, Prueger S, Foo NW, Fu EW, Lenz $M$ (2009) Termites eavesdrop to avoid competitors. Proc R Soc B 276:4035-4041

Filatova OA, Guzeev MA, Fedutin ID, Burdin AM, Hoyt E (2013) Dependence of killer whale (Orcinus orca) acoustic signals on the type of activity and social context. Biol Bull 40:790-796

Filatova OA, Miller PJO, Yurk H, Samarra FIP, Hoyt E, Matkin CO, Barrett-Lennard LG (2015) Killer whale call frequency is similar across the oceans, but varies across sympatric ecotypes. J Acoust Soc Am 138:251-257

Fish JF, Vania JS (1971) Killer whale, Orcinus orca, sounds repel white whales, Delphinapterus leucas. Fish Bull 69: 531-536

Flórez-González L, Capella JJ, Rosenbaum HC (1994) Attack of killer whales (Orcinus orca) on humpback whales (Megaptera novaeangliae) on a South American Pacific breeding ground. Mar Mamm Sci 10:218-222

Ford JKB, Reeves RR (2008) Fight or flight: antipredator strategies of baleen whales. Mammal Rev 38:50-86

Friedlaender AS, Hazen EL, Golbogen JA, Stimpert AK, Calambokidis J, Southall BL (2016) Prey-mediated behavioral responses of feeding blue whales in controlled sound exposure experiments. Ecol Appl 26:1075-1085

Fuong H, Keeley KN, Bulut Y, Blumstein DT (2014) Heterospecific alarm call eavesdropping in nonvocal, whitebellied copper-striped skinks, Emoia cyanura. Anim Behav 95:129-135

* Gero S, Whitehead H, Rendell L (2016) Individual, unit and vocal clan level identity cues in sperm whale codas. $\mathrm{R}$ Soc Open Sci 3:150372

Goldbogen JA, Southall BL, DeRuiter SL, Calambokidis J and others (2013) Blue whales respond to simulated midfrequency military sonar. Proc R Soc B 280:20130657

Guinet C, Barrett-Lennard LG, Loyer B (2000) Co-ordinated attack behavior and prey sharing by killer whales at Crozet archipelago: strategies for feeding on negativelybuoyant prey. Mar Mamm Sci 16:829-834

Herman LM (2017) The multiple functions of male song within the humpback whale (Megaptera novaeangliae) mating system: review, evaluation, and synthesis. Biol Rev Camb Philos Soc 92:1795-1818

炎Huse G, Fernö A, Holst JC (2010) Establishment of new wintering areas in herring co-occurs with peaks in the 'first time/repeat spawner' ratio. Mar Ecol Prog Ser 409: 189-198

Jefferson TA, Stacey PJ, Baird RW (1991) A review of killer whale interactions with other marine mammals: predation to co-existence. Mammal Rev 21:151-180

Jensen FH, Marrero Perez J, Johnson M, Aguilar Soto N, Madsen PT (2011) Calling under pressure: short-finned pilot whales make social calls during deep foraging dives. Proc R Soc B 278:3017-3025

Johnson MP, Tyack PL (2003) A digital acoustic recording tag for measuring the response of wild marine mammals to sound. IEEE J Oceanic Eng 28:3-12

Johnson M, Aguilar de Soto N, Madsen PT (2009) Studying the behaviour and sensory ecology of marine mammals using acoustic recording tags: a review. Mar Ecol Prog Ser 395:55-73

Jourdain E, Vongraven D (2017) Humpback whale (Megap- tera novaeangliae) and killer whale (Orcinus orca) feeding aggregations for foraging on herring (Clupea harengus) in northern Norway. Mamm Biol 86:27-32

* Jourdain E, Vongraven D, Bisther A, Karoliussen R (2017) First longitudinal study of seal-feeding killer whales (Orcinus orca) in Norwegian coastal waters. PLOS ONE 12:e0180099

Kern JM, Laker PR, Radford AN (2017) Contextual variation in the alarm call responses of dwarf mongooses, Helogale parvula. Anim Behav 127:43-51

King SL, Friedman WR, Allen SJ, Gerber L and others (2018) Bottlenose dolphins retain individual vocal labels in multi-level alliances. Curr Biol 28:1993-1999.e3

Kvadsheim PH, Lam FP, Miller P, Sivle LD and others (2015) The $3 \mathrm{~S}^{2}$ experiments - studying the behavioral effects of naval sonar on northern bottlenose whales, humpback whales and minke whales. FFI report 2015/01001. Norwegian Defence Research Establishment, Horten

LaGory KE (1987) The influence of habitat and group characteristics on the alarm and flight response of whitetailed deer. Anim Behav 35:20-25

* Latinne P, Debeir O, Decaestecker C (2001) Limiting the number of trees in random forests. In: Kittler J, Roli F (eds) Proc 2nd Int Workshop Multiple Classifier Syst, 2-4 July 2001, Cambridge. Springer, Berlin, p 178-187

Liaw A, Wiener M (2002) Classification and regression by randomForest. R News 2:18-22

KLima SL, Dill LM (1990) Behavioral decisions made under the risk of predation: a review and prospectus. Can J Zool 68:619-640

*Magrath RD, Haff TM, McLachlan JR, Igic B (2015) Wild birds learn to eavesdrop on heterospecific alarm calls. Curr Biol 25:2047-2050

*McCordic JA, Todd SK, Stevick PT (2014) Differential rates of killer whale attacks on humpback whales in the North Atlantic as determined by scarification. J Mar Biol Assoc UK 94:1311-1315

*McGregor PK (1993) Signalling in territorial systems: a context for individual identification, ranging and eavesdropping. Philos Trans R Soc B 340:237-244

*Miller PJO (2006) Diversity in sound pressure levels and estimated active space of resident killer whale vocalizations. J Comp Physiol A 192:449-459

* Miller PJO, Johnson MP, Tyack PL (2004) Sperm whale behaviour indicates the use of echolocation click buzzes 'creaks' in prey capture. Proc Biol Sci 271:2239-2247

Miller PJO, Shapiro AD, Deecke VB (2010) The diving behaviour of mammal-eating killer whales (Orcinus orca): variations with ecological not physiological factors. Can J Zool 88:1103-1112

Naessig PJ, Lanyon JM (2004) Levels and probable origin of predatory scarring on humpback whales (Megaptera novaeangliae) in east Australian waters. Wildl Res 31: 163-170

Nousek AE, Slater PJB, Wang C, Miller PJO (2006) The influence of social affiliation on individual vocal signatures of northern resident killer whales (Orcinus orca). Biol Lett 2:481-484

* Palmer MS, Gross A (2018) Eavesdropping in an African large mammal community: antipredator responses vary according to signaller reliability. Anim Behav 137:1-9

‘ Payne KB, Thompson M, Kramer L (2003) Elephant calling patterns as indicators of group size and composition: the basis for an acoustic monitoring system. Afr J Ecol 41: 99-107 
Perla BS, Slobodchikoff CN (2002) Habitat structure and alarm call dialects in Gunnison's prairie dog (Cynomys gunnisoni). Behav Ecol 13:844-850

Pfefferle D, Fischer J (2006) Sounds and size: identification of acoustic variables that reflect body size in hamadryas baboons, Papio hamadryas. Anim Behav 72:43-51

Pitman RL, Deecke VB, Gabriele CM, Srinivasan M and others (2017) Humpback whales interfering when mammal-eating killer whales attack other species: mobbing behavior and interspecific altruism? Mar Mamm Sci 33: 7-58

Pollock HS, Martínez AE, Kelley JP, Touchton JM, Tarwater CE (2017) Heterospecific eavesdropping in ant-following birds of the Neotropics is a learned behaviour. Proc R Soc B 284:20171785

R Core Team (2017) R: a language and environment for statistical computing. R Foundation for Statistical Computing, Vienna. www.r-project.org/

Rankin S, Archer F, Barlow J (2013) Vocal activity of tropical dolphins is inhibited by the presence of killer whales, Orcinus orca. Mar Mamm Sci 29:679-690

KSamarra FIP, Vighi M, Aguilar A, Vikingsson GA (2017) Intra-population variation in isotopic niche in herringeating killer whales off Iceland. Mar Ecol Prog Ser 564: 199-210

Scheidat M, Castro C, Gonzalez J, Williams R (2004) Behavioural responses of humpback whales (Megaptera novaeangliae) to whalewatching boats near Isla de la Plata, Machalilla National Park, Ecuador. J Cetacean Res Manag 6:63-68

Simon M (2005) Acoustic characteristics of underwater tail slaps used by Norwegian and Icelandic killer whales (Orcinus orca) to debilitate herring (Clupea harengus). J Exp Biol 208:2459-2466

Sivle LD, Kvadsheim PH, Curé C, Isojunno S and others (2015) Severity of expert-identified behavioural responses of humpback whale, minke whale, and north-

Editorial responsibility: Elliott Hazen,

Pacific Grove, California, USA

Reviewed by: 3 anonymous referees ern bottlenose whale to naval sonar. Aquat Mamm 41: 469-502

Smith JN, Goldizen AW, Dunlop RA, Noah MJ (2008) Songs of male humpback whales, Megaptera novaeangliae, are involved in intersexual interactions. Anim Behav 76: $467-477$

Southall BL, Finneran JJ, Reichmuth C, Nachtigall PE and others (2019) Marine mammal noise exposure criteria: updated scientific recommendations for residual hearing effects. Aquat Mamm 45:125-232

Stamation KA, Croft DB, Shaughnessy PD, Waples KA, Briggs SV (2009) Behavioral responses of humpback whales (Megaptera novaeangliae) to whale-watching vessels on the southeastern coast of Australia. Mar Mamm Sci 26:98-122

Steiger GH, Calambokidis J, Straley JM, Herman LM and others (2008) Geographic variation in killer whale attacks on humpback whales in the North Pacific: implications for predation pressure. Endang Species Res 4: $247-256$

Strobl C, Boulesteix AL, Kneib T, Augustin T, Zeileis A (2008) Conditional variable importance for random forests. BMC Bioinformatics 9:307

光 Übernickel K, Tschapka M, Kalko EKV (2013) Selective eavesdropping behaviour in three Neotropical bat species. Ethology 119:66-76

*Wascher CAF, Szipl G, Boeckle M, Wilkinson A (2012) You sound familiar: carrion crows can differentiate between the calls of known and unknown heterospecifics. Anim Cogn 15:1015-1019

Wensveen PJ (2012) The effects of sound propagation and avoidance behaviour on naval sonar levels received by cetaceans. MSc thesis, University of Saint Andrews. http://hdl.handle.net/10023/3194

*Wensveen PJ, Thomas L, Miller PJO (2015) A path reconstruction method integrating dead-reckoning and position fixes applied to humpback whales. Mov Ecol 3:31

Submitted: May 20, 2020

Accepted: November 23, 2020

Proofs received from author(s): February 9, 2021 